\title{
LISTERIOSIS CASE STUDY - VARIATION AND LONGEVITY FOR CURRICULUM ENHANCEMENT
}

\author{
Cheryl Newton, Christine Moresoli, Mary Robinson, and Katharina Hassel \\ University of Waterloo, Waterloo, Ontario, Canada \\ cheryl.newton, cmoresoli, mary.robinson, katharina.hassel @uwaterloo.ca
}

\begin{abstract}
Both teaching and learning from case studies enriches the engineering curriculum by connecting the classroom to real world complexities. A case study about the 2008 Listeriosis outbreak at the Maple Leaf Foods facility in Toronto was developed for the Food Process Engineering course, ChE 564. ChE 564 is a fourth-year technical elective in Chemical Engineering at the University of Waterloo (Waterloo), offered once every winter term. The Listeriosis case was developed by Waterloo Cases in Design Engineering (WCDE) from publicly-available sources.

The WCDE Listeriosis case study has been used in four offerings of ChE 564 by three instructors, from 2013 to 2016. Factors that influenced the successful transfer of teaching material are explored using instructor reflection, classroom observations, and student feedback. The three instructors reflected on these factors between each offering of the course and adapted their teaching methodologies to align with the learning outcomes for the course.

The evolution of the WCDE Listeriosis case study and its longevity will be discussed over the four course offerings. Issues such as student expectations, the role of the instructor, the open-ended nature of the case, class size, and class engagement are discussed as well. The success and challenges of the Listeriosis case study have broader implications on the difficulties of transferring material between terms and instructors while balancing variation for different cohorts. One challenge when developing case study material is balancing the time invested with the rewards in the classroom and the uptake by different instructors and/or courses.
\end{abstract}

Keywords: Case Study: Student Learning and Feedback: Instructor Reflection

\section{INTRODUCTION}

Case studies enable students to learn by doing and puts emphasis on the students' own responsibility for their learning. A case study details the complexity and context of a real-world challenge. Cases are often ambiguous, uncertain, inherently complex, often incomplete and multidisciplinary; they provide students the opportunity to 'live' the challenge. Teaching using cases can involve many educational philosophies and techniques. Typically, the term case method refers to a learning experience where a significant percentage of class time is spent on discussion. The case method connects theory and concepts to practice while engaging students. Skills developed using the case method include critical thinking, problem solving, communication and decision-making [1].

Cases have been used in engineering curricula since the 1970s but the traditional lecture method continues as the most widely used mode of instruction. A drawback of available engineering case studies is that often they are not readily useable by faculty members and cases need to be developed or modified for classroom instruction [2]. Case-based teaching is an inductive approach that requires the student to solve a problem and formulate opinions for a real-life scenario [3]. A gap between theory and practice can occur if students are unable to relate theory to realworld problems [4].

Final year engineering courses such as technical electives represent an attractive venue to introduce cases and expose students to real applications of engineering. In the Food Process Engineering technical elective in Chemical Engineering (ChE 564), a case study was introduced to expose students to real world practical situations and promote their learning and engagement. Course content includes food characteristics, food safety, preservation operations, and selected topics. The case study topic was proposed by the course instructor to Waterloo Cases in Design Engineering (WCDE). Over the past four course offerings, the case study has evolved based on student and instructor feedback. The first two course offerings had students present as a group on one of four technical topics outlined in the case study. The 
second two course offerings followed a more traditional case method approach where students worked in small groups to prepare a report on one of four technical topics, individually prepared for a class case discussion, and participated in a large group discussion on the case study.

\section{METHODOLOGY}

A case study was identified as a good fit for the ChE 564 course in order to provide a real-life example to students on various food processing topics that have direct implementations on public safety. The goal of incorporating the case study was to further develop the students' understanding of food safety while integrating their prior knowledge and encourage reflection on the role and responsibilities of an engineer.

\subsection{Case Development}

The WCDE 2008 Listeriosis outbreak at Maple Leaf Foods involved contamination of ready-to-eat deli products in a Toronto, Canada, manufacturing facility. As a result of the contamination, 57 confirmed cases of listeriosis infection resulted, including 22 fatalities. Maple Leaf was highly visible to the public throughout the outbreak crisis and communicated their commitment to solving the issue and preventing future food safety incidents [6]. An independent inquiry was completed and the report made available to the public, this report is the main source for the case study background and intended as a main student reference in completing the case study and associated assignment [5]. No contact was made with Maple Leaf for the development of the case study.

The case study had the following learning outcome: to conduct a critical analysis of the manufacture of ready-toeat meat products by considering the case study with respect to the following four topics: Listeria growth prediction, environmental testing, meat equipment operation and cleaning, and Hazard Analysis Critical Control Point (HACCP) system.

\subsection{Case Implementation}

The case study was administered over a four-year period and used to teach 118 senior level undergraduate engineering students from 2013 to 2016. Class size ranged from 18 to 39 students; a summary of the case implementation details is in Table 1.
Table 1: Case implementation summary by year.

\begin{tabular}{|c|c|c|}
\hline Year & Case Use & $\begin{array}{l}\text { Student } \\
\text { Numbers }\end{array}$ \\
\hline 2013 & \multirow{2}{*}{ Case Presentations } & 18 \\
\hline 2014 & & 32 \\
\hline 2015 & \multirow{2}{*}{$\begin{array}{l}\text { Case Method discussion, group } \\
\text { and individual assignment }\end{array}$} & 29 \\
\hline 2016 & & 39 \\
\hline
\end{tabular}

Students applied the following food processing focus areas using the case study for context:

1. Listeria growth prediction

2. Environmental testing

3. Meat equipment operation and cleaning

4. HACCP

Growth prediction, equipment operation and cleaning, and HACCP were introduced in course material. The topic of environmental testing was not covered in course material and introduced to the class only through the case study. The case study provides an opportunity for students to delve deeper into these topics and apply them critically in a real-life situation.

Case implementation over the successive course offerings followed a cycle wherein changes to the case delivery mode, case assignment and student assessment reflected student and instructor feedback from previous implementations, Fig. 1. Changes to the case delivery mode, case assignment, and student assessment were done based on student and instructor feedback.

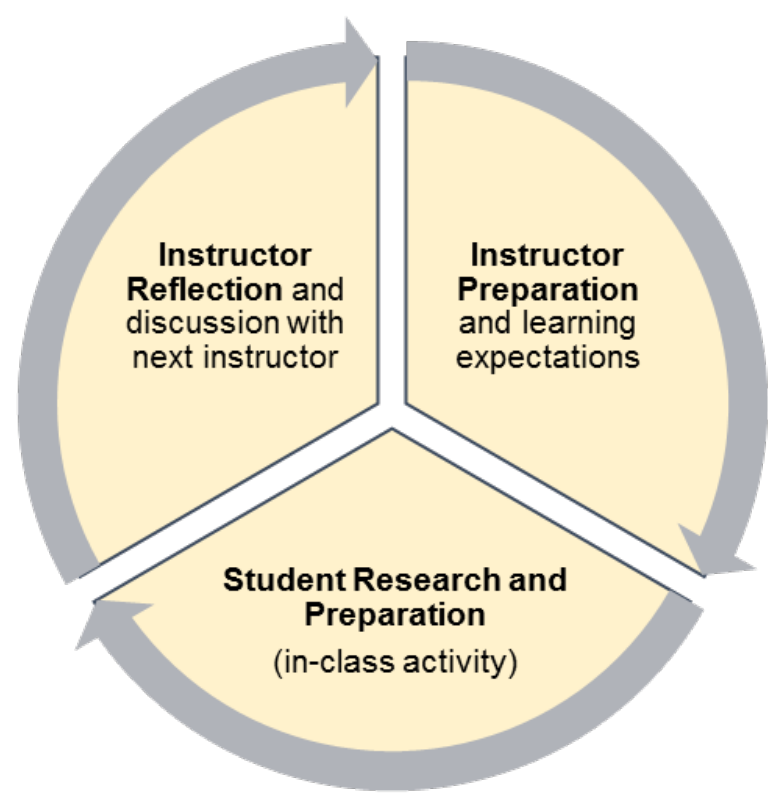

Fig. 1 Case implementation cycle. 
The process begins by the instructor defining learning expectations for the students from the case study. Student preparation includes the completion of a case assignment following instructions created by the instructor to meet the desired learning outcomes. Next, the student results are compared to the instructor's expectations. Based on whether or not the instructor's learning expectations were met, refinement of the student activity and format will be made for the next case offering.

Student survey feedback was collected for quality assurance to assess the effectiveness of the case study for the four case offerings and to improve the case teaching method.

\section{RESULTS}

The four course-case offerings can be grouped by the two case implementation methods used: case presentations and modified case method. Based on instructor reflection and student feedback from 2013 and 2014, the case study implementation was changed to a series of three deliverables: a group report assignment, an individual reading assignment, and a class discussion.

\subsection{Initial case offering - Case Presentations (2013 and 2014)}

The first method used for case study implementation was a series of case presentations. Students, in selfselected groups of three, were asked to conduct a critical analysis of the manufacture of ready-to-eat meat products by considering the WCDE 2008 Canadian Listeriosis Outbreak case study. The instructor's expectations were for students' projects to critically review one of the four topics by making reference to chemical engineering principles and tools, microbiology, ingredients, and regulations where appropriate, and produce a presentation to be shared with the class. The presentation was to be based on current scientific/technical references (minimum of 6) published in the past 10 years, including post 2008. The instructor and student preparation involved the following steps:

1. Students were provided with the case-study document

2. Students were to form groups (three students maximum) and select a specific topic (maximum two groups/topic) (one week to complete task)

3. Groups were to prepare and submit presentations about their selected topics prior to the class (three weeks after topic selection)

4. Ten minute in-class group presentation and three minute question period - same topic presented twice (different perspectives)
5. Follow-up with in-class paper survey for student feedback

Evaluation for the case presentations was grouped into content, resources, delivery, and questions, Table 2. During the class presentations, students were given the opportunity to ask questions to the presenters. The instructor found student engagement was topic- and/or group-specific. The presentations reflected a thorough grasp of previous in-class HACCP material (one of the four topics), previous co-op experience, and limited connection of case topics to course material on growth prediction.

Table 2: Case presentation evaluation.

\begin{tabular}{|l|c|}
\hline Topic & Weighting \\
\hline $\begin{array}{l}\text { Structure (introduction, presentation } \\
\text { \& analysis of information, conclusion) }\end{array}$ & $40 \%$ \\
\hline $\begin{array}{l}\text { Scientific/Technical Resources } \\
\text { (quality and variety) }\end{array}$ & $20 \%$ \\
\hline $\begin{array}{l}\text { Delivery (visual aids, contact with the } \\
\text { audience, level of preparation) }\end{array}$ & $20 \%$ \\
\hline $\begin{array}{l}\text { Questions (questions in other } \\
\text { presentations, answers \& } \\
\text { professionalism) }\end{array}$ & $20 \%$ \\
\hline
\end{tabular}

The survey included three measures: engaging application, appreciation of relevance, and understanding of course topics. Students were asked to evaluate the survey items using a typical five-level Likert scale ranging from strongly agree to strongly disagree, Table 3. In addition, students were given the option to provide written comments on each item. The questions were asked once, after the case study assignment was completed.

Student feedback on the case study was overall very positive. Students enjoyed learning from the case study and applying classroom knowledge to a real-life case. Students reflected on a heightened awareness about the necessary food safety procedures in the work place. They noted the key role that the group discussion played in providing them with a full understanding of the case topics from the multiple points of view presented by their peers. 
Table 3: Student feedback 2013 and 2014.

\begin{tabular}{|l|c|c|}
\hline \multirow{2}{*}{ Question } & \multicolumn{2}{|l|}{$\begin{array}{l}\text { Agree/Strongly } \\
\text { Agree }\end{array}$} \\
\cline { 2 - 3 } & $\begin{array}{l}2013 \\
(\mathrm{n}=18)\end{array}$ & $\begin{array}{l}2014 \\
(\mathrm{n}=24)\end{array}$ \\
\hline $\begin{array}{l}\text { This Case Study was an } \\
\text { engaging application of these } \\
\text { specific topics }\end{array}$ & $88 \%$ & $88 \%$ \\
\hline $\begin{array}{l}\text { This Case Study improved } \text { my } \\
\text { appreciation of the relevance of } \\
\text { these specific course topics. }\end{array}$ & $100 \%$ & $92 \%$ \\
\hline $\begin{array}{l}\text { This Case Study helped me } \\
\text { understand these specific } \\
\text { course topics }\end{array}$ & $100 \%$ & $88 \%$ \\
\hline $\begin{array}{l}\text { Small group discussion(s) of } \\
\text { the Case Study helped me } \\
\text { understand these specific course } \\
\text { topics }\end{array}$ & $76 \%$ & - \\
\hline $\begin{array}{l}\text { Questions addressed to the } \\
\text { presenters helped me understand } \\
\text { these specific course topics }\end{array}$ & - & $30 \%$ \\
\hline
\end{tabular}

Based on the presentations and questions asked and answered, the instructor recognized the differing comfort levels students had in responding to open ended questions and relating prior knowledge to the case. As a result, the instructor recognized that it was important not to assume that all students have the comfort to handle open ended questions and the ability to relate to prior knowledge. For the next case offerings, more directions were provided to ensure that the expected course knowledge is included in the group presentations. The instructor found that the open-ended nature of critical analysis can be challenging for students to complete to meet the desired case learning outcome.

For the 2014 course offering the following changes were made to the instructor and student preparation:

1. Students were provided with the WCDE case study document and the instructor added one technical reference for each of the four case study focus areas to be studied.

2. The number of groups permitted to pick a topic was increased to three groups per topic to accommodate the increased class size.

3. In-class group presentation time was shortened to eight minutes and three minutes for questions. Groups were assigned to ask questions of a particular presentation.

The instructor of the 2014 offering found that the case presentations for this offering reflected an improvement in the understanding of course topics. The provision of the initial references appears to have improved the technical content of the presentations. The instructor felt more probing questioning from having assigned groups increased perspectives within a given topic. However, the student feedback reflected $30 \%$ strongly agree and agree with the usefulness of questions during the presentations, Table 3 . Overall, due to the larger class size the multiple oral presentations of the same topic is not optimal and this was reflected in the student written feedback.

The 2015 instructor decided to use the WCDE Listeriosis case study in ChE 564 but in a different format. The purpose of this change was to prevent passive engagement to active participation in all four of the aspects of the 2008 Listeriosis outbreak.

\subsection{Modified case offering- Case Method (2015)}

Based on the feedback from the previous two case implementations, a new format for the in-class activity was chosen. A new course instructor taught the 2015 offering and decided to follow a modified version of the traditional case method approach to deliver the WCDE Listeriosis case study. The case study was implemented using the following structure:

1. Students were provided with the case-study document.

2. Students were to form groups of $2-3$ to research one of the four subject areas and produce a 3page research paper. This review should be based on current scientific and/or technical references (minimum of 6, published in the last 10 years and the students were provided with a starting point paper).

3. Research papers were posted on the Learning Management System (LEARN) for all students to read before the in-class discussion. Students had 5 days to review the reports prepared by the other groups and consider the information presented by following a set of "reading questions" provided by the instructor. Students could complete the review of the reports individually or in their small groups. Evidence of this review was to be posted to LEARN by the night before the in-class discussion.

4. 2-hour in-class discussion, moderated by the course instructor. Approximately 20 minutes was spent on each of the four topic areas.

5. Follow-up survey.

All groups submitted research papers (small-group activity) and the majority of students completed the reading questions (individual preparation) in order to prepare for the class discussion. The majority of the class attended and participated in the group discussion; as luck 
would have it, the day of the in-class discussion was also the day of the worst winter storm of the year. Table 4, the student evaluation for the case assignment was worth $10 \%$ of the final grade.

Table 4: Case method evaluation.

\begin{tabular}{|l|c|}
\hline & Weighting \\
\hline $\begin{array}{l}\text { Short Report (quality of writing, } \\
\text { presentation of information, formatting, } \\
\text { citations, including introduction and } \\
\text { concluding statements) }\end{array}$ & $80 \%$ \\
\hline $\begin{array}{l}\text { Reading Questions (Credit/no credit } \\
\text { for submitting notes from reading other } \\
\text { groups' short reports) }\end{array}$ & $10 \%$ \\
\hline $\begin{array}{l}\text { In-class participation (Credit/no } \\
\text { credit for being present and } \\
\text { participating at least once) }\end{array}$ & $5 \%$ \\
\hline $\begin{array}{l}\text { Feedback Survey (Credit/no credit for } \\
\text { taking the survey) }\end{array}$ & $5 \%$ \\
\hline
\end{tabular}

Student feedback from the survey was generally favourable of the case study, Table 5.

Table 5: Student feedback 2015 and 2016.

\begin{tabular}{|l|c|c|}
\hline \multirow{2}{*}{$\begin{array}{l}\text { Question: How do you feel } \\
\text { about how the case study was }\end{array}$} & \multicolumn{2}{|l|}{$\begin{array}{l}\text { Agree/Strongly } \\
\text { Agree }\end{array}$} \\
\cline { 2 - 3 } run? & $\begin{array}{l}2015 \\
\text { (n= 22) }\end{array}$ & $\begin{array}{l}2016 \\
\text { (n = 29) }\end{array}$ \\
\hline $\begin{array}{l}\text { I think that the Listeriosis Case } \\
\text { Study should be used in future } \\
\text { offerings of ChE 564 }\end{array}$ & $90 \%$ & $89 \%$ \\
\hline $\begin{array}{l}\text { I feel that the research portion of } \\
\text { this case study (researching and } \\
\text { preparing the mini-report) was } \\
\text { beneficial to my learning }\end{array}$ & $80 \%$ & $93 \%$ \\
\hline $\begin{array}{l}\text { I feel that the preparation before } \\
\text { the in-class discussion (reading } \\
\text { reports and answering } \\
\text { questions) was beneficial to my } \\
\text { learning }\end{array}$ & $80 \%$ & $76 \%$ \\
\hline $\begin{array}{l}\text { I feel that the in-class discussion } \\
\text { was beneficial to my learning }\end{array}$ & $65 \%$ & $64 \%$ \\
\hline $\begin{array}{l}\text { I prefer this style of case study } \\
\text { to a traditional assignment }\end{array}$ & $70 \%$ & $38 \%$ \\
\hline
\end{tabular}

\subsection{Modified Case Method - 2016}

Based on the 2015 implementation, a new instructor planned to adopt the case method style for the 2016 course offering. The class size was almost $35 \%$ larger than the 2015 class, Table 1 . The instructor reflected on the required preparation:

1. Supply well organized documents, outlining the steps of the project (topic selection, topic summary, reading other groups summary, answering reading questions, participating in class discussion).

2. Go over timeline and expectations in class as well as having documents available online.

3. Remind students of deadlines.

4. Prepare agenda for day of class discussion (name tags, room design, introductions, sequence of discussion).

5. Prepare question for each topic to ask in case the discussion fades or gets misguided.

6. Other than that, do not interfere, and take on observer role.

The student preparation for the case study deliverables included the following aspects:

1. Find group partners.

2. Decide on one of the four topics.

3. Prepare a short report over 2-2.5 weeks (3 pages, summarizing findings) (one per group).

4. One week to study other groups summaries and submit answer to reading questions for each topic (one per group or individual).

5. Participate during the in-class discussion (not only during the section the group prepared but also during other sections).

6. Fill out the feedback survey.

Student feedback was overall positive regarding the case offering (Table 5). The main departure from the previous feedback was that student preference to case based learning over traditional lectures dropped to $38 \%$ from the $70 \%$ preference in 2015. The 2016 class size increase compared to 2015 may have played a role in affecting the student's preference and experience of the case study. The challenge of a larger class was evident in the class discussion format; student feedback included multiple instances of frustration regarding minimal moderation and some monopoly of the discussion by the same classmates. A student suggestion to minimize discussion monopolization would be to go around the classroom asking each student to give one takeaway they had from the case study. 


\section{DISCUSSION}

\subsection{Case Development Reflection}

The Listeriosis case study has been used in four course offerings of ChE 564 by three different instructors. The WCDE case development process requires a balance of case development effort with potential course and student impact especially when case implementation success is unknown until classroom use. A challenge faced by WCDE is whether or not different course instructors will use the same case material. A factor of success in the use of the WCDE Listeriosis case study is the clear alignment of case study with course material. Collaborating with the course instructor in the early planning stages, as was done in this situation, can lead to case study longevity since the case is directly aligned and bridged into the course material.

Picking a case study and topic with readily accessible material to students is also an important consideration. In the Listeriosis case study, the openness of Maple Leaf throughout the outbreak made information, otherwise not typically available outside an organization, available publically. Student feedback suggested that choosing a topic with direct implications on a student's daily life also lends itself to increasing the student's comfort in assuming the role of case decision maker.

Having well-organized course material is seen by the course instructors and authors of this paper to improve uptake by different instructors teaching the same course. The WCDE group develops case studies and releases them for use at Waterloo; select cases are available for use in other educational institutions. The teaching note, a document accompanying the case study intended to provide the instructor with guidance for case use, is updated with case implementation. WCDE case studies also have solution modules that can assist with case study assignment preparation and provide supplemental instructional materials not given in the case study itself. For the WCDE Listeriosis case study, the solution module topics of Food Safety and HACCP Analysis were used by instructors to provide a summary of the case study's key takeaways. Instructor inclination towards case study learning is the main factor lending to successful case study implementation and case uptake. It is up to the instructor to choose whether or not they will adopt a case-based style of teaching.

Having cases tailored for courses can be an advantage as well as a limiting factor. The WCDE Listeriosis case study has been implemented in one other course at Waterloo, Quality Management and Control (MSCI 551). For the MSCI 551 implementation, is was necessary to outline a new problem statement for the case study to be more relevant to the course material and course learning objectives. A supplemental case assignment was prepared by a WCDE staff member for this case implementation. For the Listeriosis case, the problem statement focus was changed from food safety to topics relating to Statistical Process Control (SPC) and continuous improvement methodologies such as Six Sigma [7]. Having adequate support for case study customization is a key factor in new and extended use of engineering case studies at Waterloo.

\subsection{Instructor Reflection}

For the individual and small group aspect of the case study it was important to set clear expectations and give a starting point (in the form of an example paper). The case assignment was left open-ended so that students could add their own twist.

Some of the challenges the instructors faced regarding the group discussion was how to moderate the discussion and classroom space limitations. Ideally, a round table style set-up should be used for a large-group discussion, which was how the classroom was arranged. For difficultto-grasp concepts such as growth prediction, environmental testing and equipment cleaning, a class example could be given before the case study assignment. Implementing a student suggestion of going around the classroom to give everyone an opportunity to participate might end up being quite repetitive.

The continued use of the case study in ChE 564 has the consensus of all three instructors. The evolution of the case implementation benefited from the diverse background and perspectives of the three instructors. The key elements in improving the benefits of students learning from the case study reside in the openness of the three instructors and their ability to address the shortcomings of the previous offering. When implementing case studies in the classroom, instructors need to realize the shift in their role, as facilitator in contrast to lecturer. These two roles require different sets of skills. Instructors should also realize the importance of guiding the students in their learning by decomposing the learning into manageable steps.

\subsection{Recommendations}

For the next course offerings, the authors recommend continued implementation using the case method style. Future instructors should use additional moderation in the class discussion and ask for student moderators (one for each topic) to keep the topic of discussion from straying too far off-topic. Less involvement of the course instructor in the discussion by using student moderators is seen as ideal. For student moderators, training or help with moderation is required. For students to take on a moderator role they will need much more exposure to case 
studies run by experienced moderators. Also, clear guidelines for large class discussion will be developed.

Overall, engineering undergraduate students found the case study experience in the past four years beneficial to their learning, but based on 2015 and 2016 data they are still unsure if they prefer this style of learning to traditional lectures. In 2015 and 2016 offerings, for many students, this was the first time they had seen a case study. Promoting the use of case studies in more courses and by more instructors is believed to help build student consensus on case-based learning.

\section{CONCLUSIONS}

The use of the WCDE Listeriosis case study over the past four years has given the authors reason to continue case study use in ChE 564. It has also given the authors motivation to make the teaching environment of engineering education more in touch with reality and the real-world through the use of case studies.

\section{Acknowledgements}

The authors would like to thank funding from the NSERC Chairs in Design Engineering program, through the Waterloo Cases in Design Engineering group, for support in case study development.

\section{References}

[1] L.A Maufette-Leenders, J.A. Erskine, and M.R. Leenders, Learning with Cases, Richard Ivey School of Business, 2003 ( $3^{\text {rd }}$ ed), 262 pp. \{ISBN: 0-7714-2419-1\}

[2] P.K. Raju and C.S. Sankar, "Teaching Real-World Issues through Case Studies,” Journal of Engineering Education, vol. 88, no. 4, pp. 501-508, 1999.

[3] M.J. Prince and R.M. Felder, "Inductive Teaching and Learning Methods: Definitions, Comparisons, and Research Bases,” Journal of Engineering Education, vol. 95, no. 2, pp. 122-138, 2006.

[4] G.M. Fragoso-Diaz, B. Gray, and E. Jones, "Enhancing Students' Learning Experience Using Case Studies,” in Proc. 2015 ASEE Annual Conference and Exposition, (Seattle, WA; 14-17 June 2015), 9 pp., 2015.

[5] Canadian Food Inspection Agency, "Action on Weatherill Report Recommendations to Strengthen the Food Safety System: Final Report to Canadians December 2011,” Available as of August 16, 2012 from http://www.inspection.gc.ca/food/information-forconsumers/food-safety-investigations/progress-on-foodsafety/weatherill-reportrecommendations/eng/1362425366007/1362425780005

[6] C. Pearce, "2008 Canadian Listeriosis Outbreak,” Waterloo Cases in Design Engineering, University of Waterloo, WCDE-00161-01, January 2013.

[7] L. Stacey, A. Barlatt, and S. Lambert, "Collaborating on a Case-Based Course in Quality Management and Control", in Proc. International Conference on Engineering and Product Design Education (E\&PDE15), Guy Bingham, Darren Southee, John McCardle, Ahmed Kovacevic, Erik Bohemia, Brian Parkinson (ed.) (Loughborough, United Kingdom, September 3-4, 2015), 6 pp., 2015. 